\title{
Disponibilidade de macronutrientes em cultivares de cana-de-açúcar submetidas à competição com Brachiaria brizantha
}

\author{
Macronutrients availability in sugarcane varieties grown under increasing densities of Brachiaria \\ brizantha
}

\author{
Leandro Galon ${ }^{\mathrm{I}}$ Siumar Pedro TironiI ${ }^{\mathrm{II}}$ Alexandre Ferreira da Silva ${ }^{\mathrm{II}}$ Amauri Nelson Beutler ${ }^{\mathrm{III}}$ \\ Paulo Roberto Ribeiro Rocha ${ }^{\mathrm{II}}$ Evander Alves Ferreira ${ }^{\mathrm{IV}}$ Antonio Alberto da Silva ${ }^{\text {II }}$
}

\section{RESUMO}

Objetivou-se com o trabalho verificar os teores foliares dos macronutrientes e o desenvolvimento das cultivares de cana-açúcar 'RB72454', 'RB867515' e 'SP801816' em competição com populações de Brachiaria brizantha. Os tratamentos utilizados foram: 1) cultivar de cana-de-açúcar 'RB72454' e população de B. brizantha de 0, 1, 3, 7, 15, 32 , 40, 32, 64, 92, 88 e 112; 2) 'RB867515' e 0, 1, 4, 14, 10, 18, $28,30,36,54,52$ e 72; 3) 'SP801816' e 0, 1, 3, 6, 14, 20, 24 26, 26, 32, 46 e 56 plantas $m^{-2}$. Aos 120 dias após a emergência da cultura, foi quantificada a massa seca (MS) da parte aérea da cana-de-açúcar e da B. brizantha. Aos 290 dias após a emergência (DAE), foram coletadas amostras das folhas +3 (terceira folha a partir do ápice das plantas), nas quais foram avaliadas as concentrações de nitrogênio total, fósforo, potássio, magnésio e cálcio. Com o aumento da população de B. brizantha, observou-se redução da MS somente na cultivar 'RB72454'. O aumento na população de B. brizantha reduziu a concentração de fósforo em todas as cultivares, nitrogênio em 'RB72454' e 'SP801816', potássio e magnésio para 'RB72454'. Nas populações mais elevadas de B. brizantha, houve maior competição pelos nutrientes disponíveis no meio, sendo o fósforo o mais limitante. A cultivar 'RB72454' foi a menos competitiva pelos nutrientes no solo. As cultivares apresentaram redução média de $76 \%$ na produtividade de colmos na densidade máxima de $\boldsymbol{B}$. brizantha.

Palavras-chave: competição, produtividade, Saccharum officinarum.

\section{ABSTRACT}

This trial aimed to verify foliar levels of macronutrients and development of sugarcane cultivars
'RB72454', 'RB867515' and 'SP801816' under competition with populations of Brachiaria brizantha. The field trial was installed where treatments were: 1) Sugarcane 'RB72454' and B. brizantha population of $0,1,3,7,15,32,40,32,64,92,88$ e 112; 2) 'RB867515' e 0, 1, 4, 14, 10, 18, 28, 30, 36, 54, 52 e 72; 3) 'SP801816' e 0, 1, 3, 6, 14, 20, 24, 26, 26, 32, 46 e 56 plants $\mathrm{m}^{-2}$. At 120 days after crop emergence, the crop and weed shoot dry mass (MS) was analyzed. At 290 days, samples of the $3^{\text {rd }}$ leaf were collected. From these samples, concentration of total nitrogen, phosphorus, potassium, calcium and magnesium where measured. As the competition increased, a reduction in MS was observed only for 'RB72454'. Increases in population B. brizantha caused reduction in leaf phosphorus concentration for all varieties; nitrogen reduction for ' $R B 72454$ ' and 'SP801816', as well as potassium and magnesium for 'RB72454'. There was higher competition for nutrients as $\boldsymbol{B}$. brizantha population was increased, being phosphorus the more limiting nutrient for growth under competition. The variety 'RB72454' demonstrated lower competitive ability in relation to the other ones. All varieties presented average reduction of $76 \%$ in the yield in maximum density of B. brizantha.

Key words: competition, yield, Saccharum officinarum.

\section{INTRODUÇÃO}

A cana-de-açúcar é a commodity agrícola que mais cresceu nos últimos anos no Brasil e sua área cultivada está aumentando acentuadamente em razão da sua utilização na produção de etanol e açúcar refinado, com valor econômico elevado. Muitos são

'Universidade Federal da Fronteira Sul (UFFS), Campus Erechim, 99700-000, Erechim, RS, Brasil. E-mail: leandro.galon@uffs.edu.br. Autor para correspondência

"Departamento de Fitotecnia, Universidade Federal de Viçosa (UFV), Viçosa, MG, Brasil.

"Universidade Federal do Pampa (Unipampa), Campus Itaqui, Itaqui, RS, Brasil.

IvUniversidade Federal dos Vales do Jequitinhonha e Mucuri (UFVJM), Faculdade de Ciências Agrárias, Diamantina, MG, Brasil. 
os fatores que limitam a expressão do potencial de produtividade máxima da cana-de-açúcar, dentre eles, destacam-se os bióticos e abióticos, responsáveis por diminuírem a produção da cultura. Dentre esses fatores, a interferência ocasionada pelas plantas daninhas merece atenção, pois, quando não controladas, podem causar grande limitação no potencial produtivo da cana-de-açúcar (KUVA et al., 2001), através da competição, principalmente por: água, luz, nutrientes e $\mathrm{CO}_{2}$. Em solos pouco férteis, a competição por nutrientes entre as espécies torna-se extremamente importante, principalmente quando houver sobreposição na zona de depleção das raízes da cultura e das plantas daninhas (RIZZARDI et al., 2001). Por exemplo, constatou-se que a competição de várias espécies de plantas daninhas com o tomateiro industrial resultou em alterações no acúmulo de macronutrientes, como nitrogênio, fósforo, potássio, cálcio, magnésio, enxofre e na massa seca da parte aérea da cultura (SILVA et al., 2010).

O potencial competitivo das plantas daninhas por nutrientes ou por outros fatores do meio varia em função da espécie (SILVA et al., 2010), do nível populacional (VIDAL et al., 2004), da época da emergência em relação à cultura (SILVA et al., 2009), do sistema de manejo adotado com a cultura (IKEDA et al., 2007) e das cultivares de uma mesma espécie que podem apresentar habilidades competitivas diferenciadas (GALON et al., 2007; SILVA et al., 2010). Desse modo, torna-se importante o conhecimento da habilidade competitiva das variedades de cana-deaçúcar com populações de plantas daninhas, para que seja possível prever os danos causados por uma espécie infestante presente em determinada lavoura (VIDAL et al., 2004; GALON et al., 2007; SILVAet al., 2010).

Várias espécies de plantas daninhas podem ser encontradas em lavouras de cana-de-açúcar, entre elas, destacam-se as pertencentes ao gênero Brachiaria (KUVA et al., 2001). Esse gênero pertence à mesma família botânica da cana-de-açúcar, apresentando assim elevada habilidade competitiva com a cultura em função de características morfofisiologicamente semelhantes. A B. brizantha apresenta capacidade de vegetar satisfatoriamente em solos ácidos e de baixa fertilidade (SIMÃO NETO et al., 1995), ao contrário das exigências da cana-de-açúcar.

Os nutrientes são importantes no desenvolvimento vegetal e no processo competitivo entre as espécies. Os padrões dos efeitos da competição por esse fator são determinados, em parte, por aspectos específicos dos competidores como pelas diferenças no hábito de crescimento e requerimento de nutrientes pelas espécies envolvidas (PITELLI et al.,
1983). Algumas espécies de plantas daninhas são mais competitivas com as culturas devido à sua maior eficiência na absorção e utilização de nutrientes (SILVA et al., 2010). De acordo com LAMEGO et al. (2005) o grau da interferência que as plantas daninhas ocasionam às culturas é influenciado diretamente pela população que convive com a cultura, com a variedade que será colocada em competição e também com a espécie infestante presente na área.

Verificou-se uma perda de produtividade de 1 t ha ${ }^{-1}$ de colmos de cana-de-açúcar para cada 3,70 $\mathrm{g} \mathrm{m}^{-2}$ de matéria seca acumulada pela B. decumbens (KUVA et al., 2001). Segundo RIZZARDI et al. (2001), a intensidade de competição entre raízes das plantas daninhas e da cultura pelos recursos existentes abaixo da superfície do solo depende do tipo e da disponibilidade dos recursos, da espécie vegetal e de sua capacidade em desenvolver sistema radical extenso, com diâmetro reduzido e área superficial ampla.

Desse modo, torna-se evidente que a $\boldsymbol{B}$. brizantha apresenta elevado potencial de competir com a cana-de-açúcar pelos nutrientes disponíveis no solo, sendo um dos fatores críticos na produtividade de colmos. Assim, as informações sobre o desenvolvimento e concentração de nutrientes na região foliar da cana-de-açúcar são requeridos para melhor entendimento dos problemas que influenciam na habilidade competitiva.

Portanto, a hipótese deste estudo é que, com o aumento da população de $\boldsymbol{B}$. brizantha, o prejuízo à absorção de nutrientes e à produtividade de colmos das cultivares de cana-de-açúcar aumentará. Objetivouse com o trabalho verificar os teores foliares dos macronutrientes, o desenvolvimento e a produtividade das cultivares de cana-açúcar 'RB72454', 'RB867515’ e 'SP801816' em competição com populações de $\boldsymbol{B}$. brizantha.

\section{MATERIAL E MÉTODOS}

O experimento foi conduzido a campo em um Argissolo Vermelho-Amarelo, município de Viçosa (MG), na estação de crescimento 2008/2009. O delineamento experimental utilizado foi o de blocos casualizados, com os seguintes tratamentos: 1) cultivar de cana-de-açúcar 'RB72454' e população de $\boldsymbol{B}$. brizantha de 0, 1, 3, 7, 15, 32, 40, 32, 64, 92, 88 e 112; 2) 'RB867515' e 0, 1, 4, 14, 10, 18, 28, 30, 36, 54, 52 e 72; 3) 'SP801816' e 0, 1, 3, 6, 14, 20, 24, 26, 26, 32, 46 e 56 plantas $\mathrm{m}^{-2}$, respectivamente. As populações da $\boldsymbol{B}$ brizantha foram variadas em função dos fatores como infestação, vigor, umidade, predadores, dentre outros, que impedem o estabelecimento de exatamente o 
mesmo número de plantas por área (unidade experimental). As unidades experimentais foram constituídas de seis linhas de 8,4m de largura e 5,0m de comprimento, com área total de $42 \mathrm{~m}^{2}$.

O plantio da cana-de-açúcar foi realizado em sistema convencional, na forma de cana-de-ano, com aração, gradagem e posterior sulcamento da área no espaçamento entre linhas de 1,4m. A densidade de plantio foi de 18 gemas m$^{-1}$, com a adubação de $500 \mathrm{~kg}$ ha $^{-1}$ da formulação NPK 8-28-16, realizada no sulco de plantio, mais adubação de cobertura de $160 \mathrm{~kg} \mathrm{ha}^{-1}$ de cloreto de potássio aos 150 dias após o plantio da canade-açúcar. A recomendação de adubação baseou-se nas características químicas e físicas do solo: $\mathrm{pH}\left(\mathrm{H}_{2} \mathrm{O}\right)$ 6,0; $\mathrm{P} \mathrm{e} \mathrm{K}{ }^{+}=7,4$ e $168 \mathrm{mg} \mathrm{dm}^{-3} ; \mathrm{Ca}^{2+}, \mathrm{Mg}^{2+}, \mathrm{Al}^{3+}, \mathrm{H}+\mathrm{Al}$, $\mathrm{SB}$ e capacidade de troca de cátions $(\mathrm{CTC})=4,2,0,7$, $0,0,4,46,5,33$ e $9,79 \mathrm{cmol}_{\mathrm{c}} \mathrm{dm}^{-3}$; saturação por bases $(\mathrm{V})=54 \%$; matéria orgânica $(\mathrm{MO})=2,4 \%$; argila, silte e areia $=47,32$ e $21 \%$, respectivamente,

As populações de $\boldsymbol{B}$. brizantha foram obtidas pela semeadura, 10 dias antes da emergência da cana-de-açúcar na densidade de $10 \mathrm{~kg} \mathrm{ha}^{-1}$, o que ocasionou a emergência das duas espécies em mesma época. Quando a B. brizantha encontravam-se no estádio de duas folhas a um afilho, foi realizado o estabelecimento das populações, com a aplicação de 1,44 $\mathrm{kg} \mathrm{ha}^{-1}$ do herbicida MSMA. O produto foi aplicado com uso de um pulverizador costal propelido a $\mathrm{CO}_{2}$, acoplado a uma barra de $2 \mathrm{~m}$ de comprimento, contendo quatro pontas de pulverização, modelo DG 110.02, calibrado para aspergir um volume de calda de 150 $\mathrm{L} \mathrm{ha}^{-1}$. Para o estabelecimento das populações desejadas de B. brizantha, protegeram-se as plantas com copos plásticos, para que não sofressem danos do herbicida. As plantas daninhas não objeto do estudo foram controladas com 2,4-D e arranquio manual.

Aos 120 dias após a emergência, foram quantificadas a massa da matéria seca da parte aérea (MS) da cana-de-açúcar e da B. brizantha. Para isso, foram coletadas as plantas de cana-de-açúcar em um metro e as plantas daninhas contidas em duas áreas de $0,25 \mathrm{~m}^{2}(0,5 \mathrm{x} 0,5 \mathrm{~m})$. Essas plantas foram seccionadas rente ao solo, alocadas em sacos de papel e acomodadas em estufa de secagem com circulação de ar forçado a $65^{\circ} \mathrm{C}$ até atingir massa constante.

A produtividade da cana-de-açúcar foi estimada realizando-se a contagem dos colmos que se encontravam nas quatro linhas centrais e desconsiderando $0,5 \mathrm{~m}$ das bordaduras laterais e frontais em cada parcela. Posteriormente, foram coletados, aleatoriamente, 30 colmos da área útil de cada tratamento e, em seguida, pesados. Com o peso médio de colmos e o número de colmos por área, estimou-se a produtividade de colmos por área ( $\left.\mathrm{t} \mathrm{ha}^{-1}\right)$.

Para avaliação do estado nutricional das plantas de cana-de-açúcar, foram coletadas amostras das folhas +3 (terceira folha a partir do ápice das plantas) aos 290 dias após a emergência da cultura, excluindo-se a nervura principal das folhas, de acordo com a metodologia proposta por MALAVOLTA(1997). Após secagem das amostras a $65^{\circ} \mathrm{C}$ até atingirem massa constante, procedeu-se à moagem destas em moinho de lâminas do tipo Willey, equipado com peneira fina (40mesh). Amostras do material vegetal foram submetidas à digestão nitro-perclórica. Em seguida, determinaram-se as concentrações de fósforo (P), pelo método da vitamina $\mathrm{C}$ modificado (BRAGA \& DE FELLIPO, 1974); de potássio (K), por fotometria de chama; e de cálcio ( $\mathrm{Ca}$ ), magnésio $(\mathrm{Mg})$, pelo espectrômetro de absorção atômica. Após digestão sulfúrica, o $\mathrm{N}$ total foi determinado pelo método de Kjeldahl.

Os dados foram submetidos à análise de variância pelo teste $\mathrm{F}$ e, quando significativos, procedeu-se à análise de regressão para as variáveis respostas em questão, sendo que a escolha dos modelos baseou-se na significância estatística (teste F), no ajuste do coeficiente de determinação $\left(R^{2}\right)$ e no significado biológico do modelo. Todos os testes foram efetuados a $\mathrm{P}<0,05$, utilizando-se o software Winstat versão 2.11 .

\section{RESULTADOS E DISCUSSÃO}

O aumento da população de plantas de $\boldsymbol{B}$. brizantha resultou em menor produção de massa da matéria seca da parte aérea (MS) da cana-de-açúcar na cultivar 'RB72454' (Figura 1A). Para as demais cultivares ('RB857515' e 'SP801816'), o incremento da população de plantas do competidor não ocasionou alterações na MS da cultura. Desse modo, fica evidente a menor habilidade competitiva da cultivar 'RB72454', até os 120 dias após o plantio, com a planta daninha. Ao se incrementar a população da planta daninha, observou-se maior produção de MS da B. brizantha, independentemente da cultivar de cana-de-açúcar testada (Figura 1B). Porém, a competição de $\boldsymbol{B}$. brizantha resultou em maior produção de MS com a cultivar 'RB72454', comparativamente às demais cultivares. Isso indica a menor habilidade competitiva dessa cultivar de cana-de-açúcar em relação às demais, possibilitando desse modo maior desenvolvimento das plantas daninhas. As diferenças entre cultivares na competição com plantas daninhas devem-se às características intrínsecas de cada genótipo, fato constatado em várias pesquisas (LAMEGO et al., 2005; GALON et al., 2007).

Pesquisas têm demonstrado que o aumento da população de plantas daninhas ocasionam a redução 

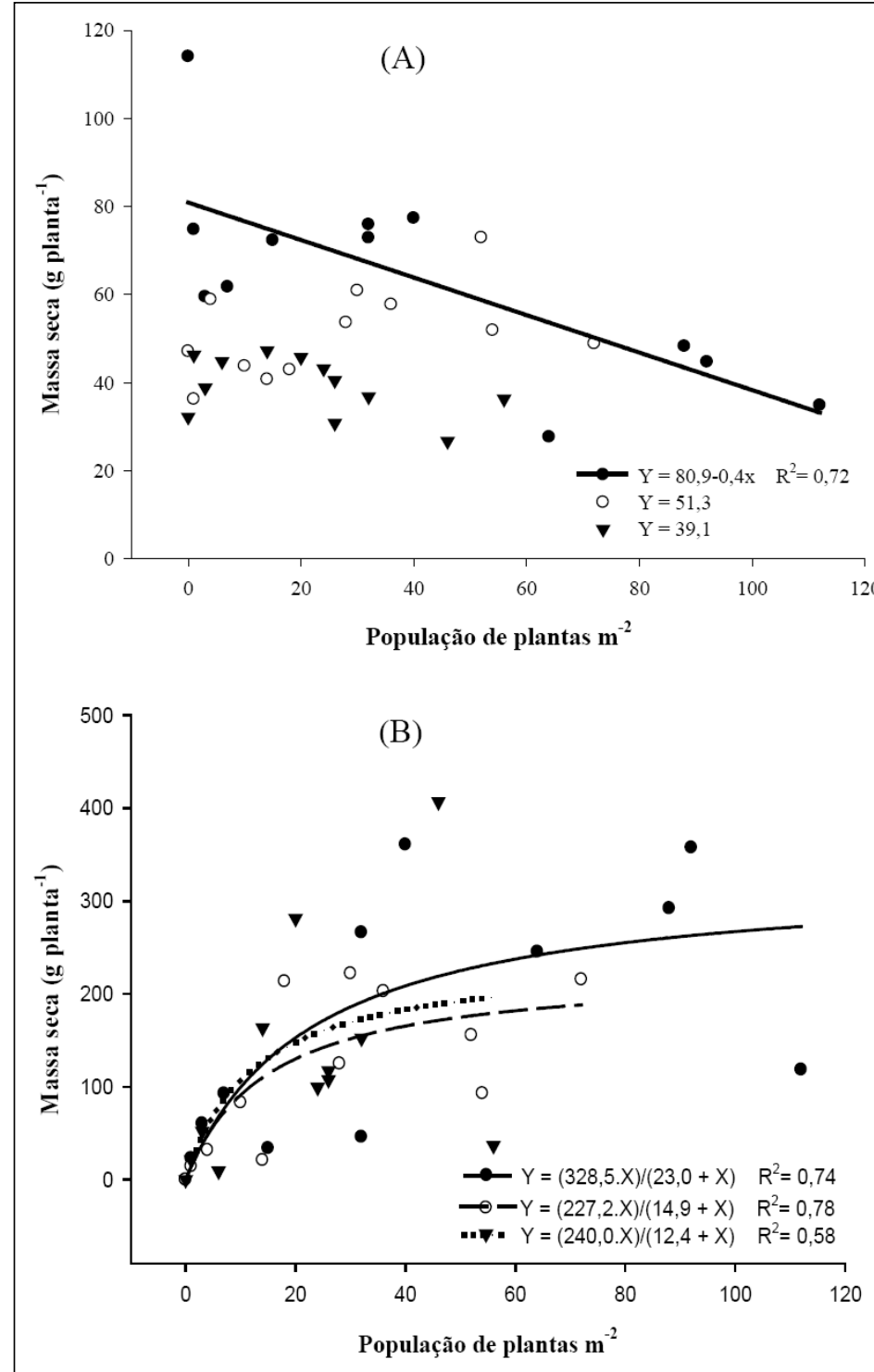

Figura 1 - Massa seca da parte aérea da cana-de-açúcar cultivares (• ) 'RB72454', (O) 'RB857515’ e ( $\nabla$ ) 'SP801816' (g planta-1) (A) e massa seca da parte aérea da Brachiaria brizantha para cada cultivar (B), na presença de populações de Brachiaria brizantha (plantas $\mathrm{m}^{-2}$ ).

da concentração de macronutrientes em soja (CARVALHO et al., 2010), massa seca da parte aérea e a produtividade de grão de soja (SILVA et al., 2009), arroz (GALON et al., 2007), sorgo (RODRIGUES et al., 2010) e cana-de-açúcar (KUVA et al., 2001). No caso específico de cana-de-açúcar, KUVA et al. (2001) observaram que o aumento da biomassa seca do capimbraquiária provocou a redução na produtividade de colmos da cultura. Os mesmos autores relataram que o acúmulo de cada $3,70 \mathrm{~g}$ de matéria seca $\mathrm{m}^{-2}$ pelo capimbraquiária proporcionou redução de $1 \mathrm{t} \mathrm{ha}^{-1}$ na produtividade da cana-de-açúcar. De acordo com
PITELLI et al. (1983), à medida que ocorre o aumento da população e do desenvolvimento das plantas daninhas, sobretudo daquelas que germinaram e emergiram no início do ciclo da cultura, intensifica-se a competição inter e intra-específica, de modo que as espécies mais altas e desenvolvidas tornam-se dominantes, ao passo que as menores são suprimidas ou morrem.

As cultivares 'RB72454' e 'SP801816' apresentaram redução na concentração foliar de nitrogênio $(\mathrm{N})$ com acréscimos da população de $\boldsymbol{B}$. brizantha (Figura 2A). No entanto, ocorreu baixa 


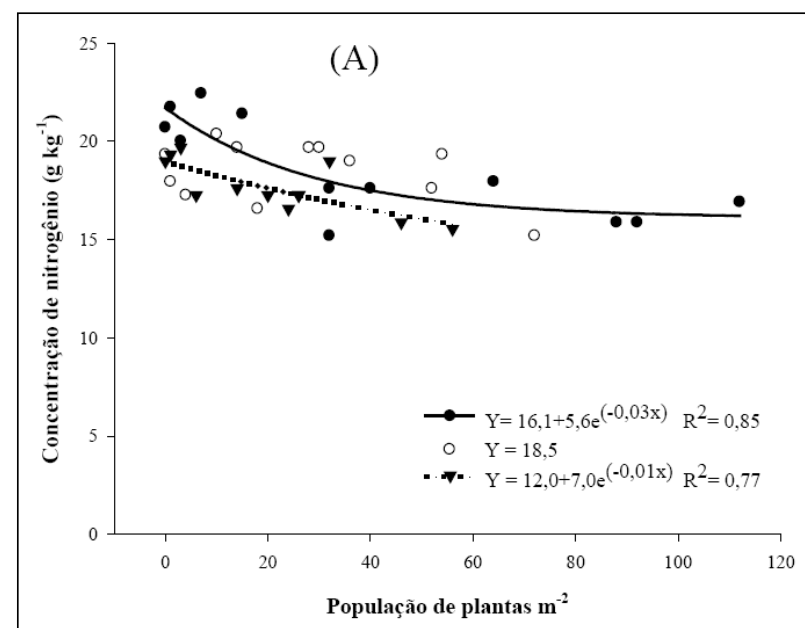

(B)
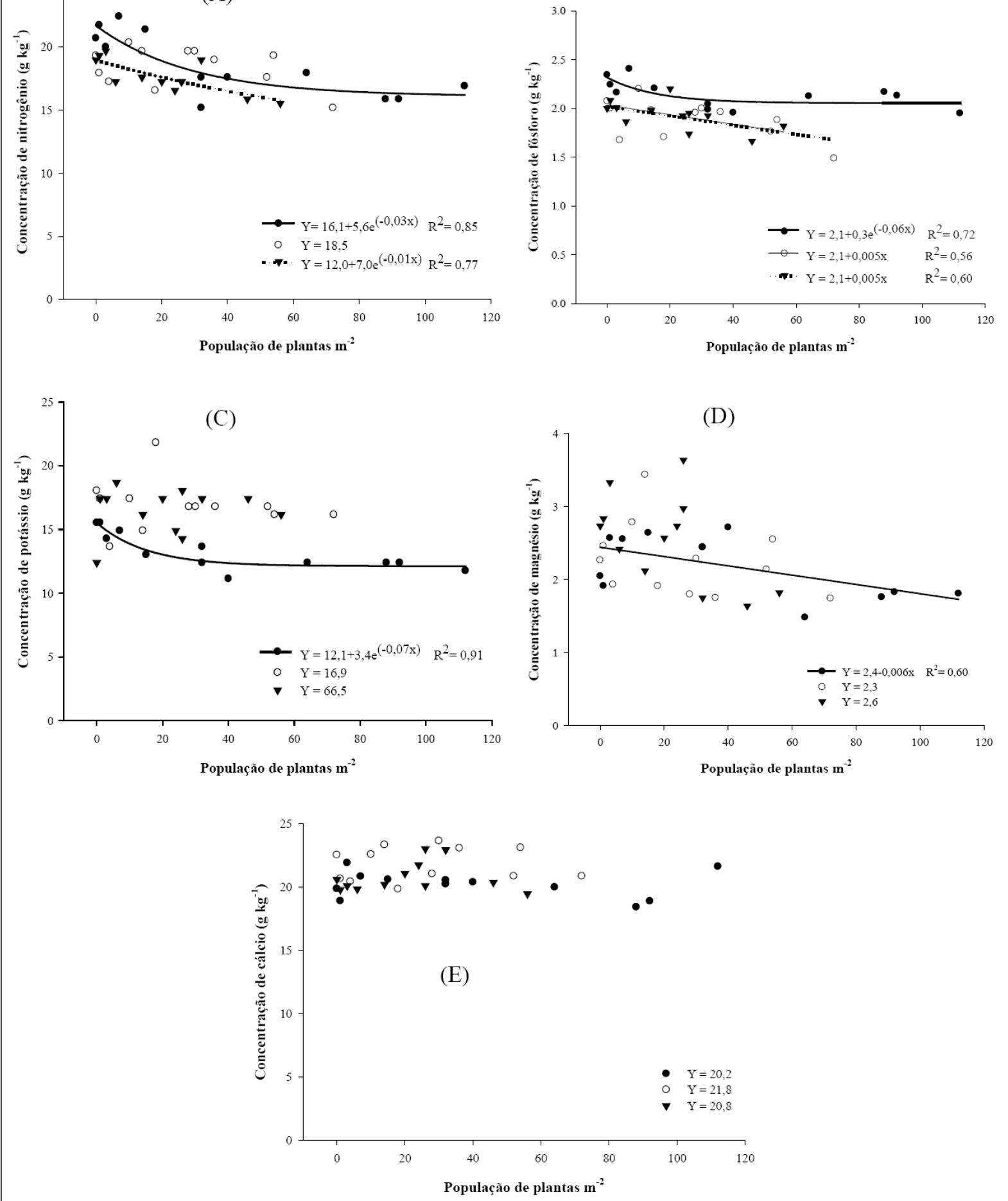

Figura 2 - Concentração foliar $\left(\mathrm{g} \mathrm{kg}^{-1}\right)$ dos nutrientes nitrogênio (A), fósforo (B), potássio (C), magnésio (D) e cálcio (E) nas plantas de cana-de-açúcar cultivares $(\bullet$ ) 'RB72454', ( O ) 'RB857515' e ( $\boldsymbol{\nabla})$ 'SP801816', em competição com populações de plantas de Brachiaria brizantha. 
interferência da planta daninha no teor de nitrogênio foliar da cana-de-açúcar, que é explicado pela presença de bactérias diazotróficas no tecido das plantas, as quais realizam a fixação do nitrogênio atmosférico. Desse modo, em geral, as plantas de cana-de-açúcar são menos dependentes desse nutriente presente no solo (REIS Jr. et al., 2000).

O aumento da população de plantas de $\boldsymbol{B}$. brizantha ocasionou redução da concentração foliar de fósforo (P), para todas as cultivares de cana-deaçúcar (Figura 2B). O P é um dos nutrientes mais limitantes para a produção da cana-de-açúcar, principalmente em solos intemperizados, que naturalmente são pobres nesse nutriente (CHIEN \& MENON, 1995). Nesse contexto, o sistema radical normalmente sofre redução quando a planta cresce em competição com plantas vizinhas, que pode ser atribuído à depleção de água ou nutrientes, liberação de substâncias tóxicas das raízes ou folhas (alelopáticas) ou produção de elementos tóxicos durante a decomposição das plantas (RIZZARDI et al., 2001). Ressalta-se também que a competição acima do solo, por luz, diminuirá o fluxo de fotossintatos para as raízes, afetando seu crescimento, sendo a $\boldsymbol{B}$. brizantha uma planta com metabolismos $\mathrm{C} 4$, como a cana-de-açúcar, desse modo, altamente exigentes pelo recurso luz, caso em que o processo de fotossíntese é ainda mais prejudicado. $\mathrm{O}$ aumento da população de espécies daninhas intensifica a competição exercida com as culturas (KUVA et al., 2001; VIDAL et al., 2004; GALON et al., 2007).

A concentração foliar de potássio $(K)$ na cultivar RB72454 decresceu em função do incremento da população de B. brizantha (Figura 2C). Para as demais cultivares estudadas, não houve efeito nos teores foliares deste nutriente em função da competição com a espécie daninha, independentemente da população de plantas, evidenciando a menor habilidade competitiva da cultivar 'RB72454' em comparação com as demais. O aumento da população de plantas daninhas ocasionou a redução do conteúdo relativo de macronutrientes nas folhas de cafeeiro, independente da espécie de planta daninha, mas com maior intensidade para Bidens pilosa (RONCHI et al., 2003). O aumento da densidade de plantas daninha promoveu a redução da concentração denutrientes das folhas de abacaxizeiro, principalmente quando em competição com Cyperus rotundus (CATUNDA etal., 2006).

A concentração foliar de magnésio (Mg) foi menor conforme houve o aumento da população de $\boldsymbol{B}$. brizantha, somente para a cultivar 'RB72454' (Figura 2D). Pode-se dizer que o acréscimo da população do competidor ocasiona maior potencial de competição e absorção de nutrientes, devido o sistema radicular mais abundante, explorando um volume maior de solo (RIZZARDI et al., 2001). Também, quando as plantas daninhas se estabelecem antes da cultura, elas tendem a dominar o ambiente, apresentando maior absorção de nutrientes, como observado para as plantas de $\boldsymbol{B}$. brizantha competindo com a cultura da soja (SILVA et al., 2009).

A concentração foliar de cálcio (Ca) nas cultivares de cana-de-açúcar não sofreu alteração com o aumento da densidade de plantas de $\boldsymbol{B}$. brizantha (Figura 2E). O cálcio é um nutriente pouco limitante quando se encontra em concentração suficiente no solo e é mais difícil haver competição entre culturas e plantas daninhas por esse elemento.

Para a produtividade de colmos de cana-deaçúcar, observou-se que as três cultivares apresentaram decréscimo à medida que se aumentou a população de B. brizantha, sendo a 'RB72454' a mais afetada em relação às demais (Figura 3 ). A produtividade de colmos das variedades 'RB72454', 'RB857515' e 'SP801816’ foram, respectivamente, 83, 80 e 66\% maiores ao se comparar a ausência de plantas de $\boldsymbol{B}$. brizantha infestando a cultura em relação à presença da população máxima da referida planta daninha. A produtividade média de colmos das três cultivares, na ausência de plantas daninhas foi de $95 \mathrm{tha}^{-1}$, comparativamente a $22 \mathrm{t} \mathrm{ha}^{-1}$ na presença da $\boldsymbol{B}$. brizantha, ocorrendo, desse modo, uma redução média de $73 t h^{-1}$. Redução aproximada de $86 \%$ na

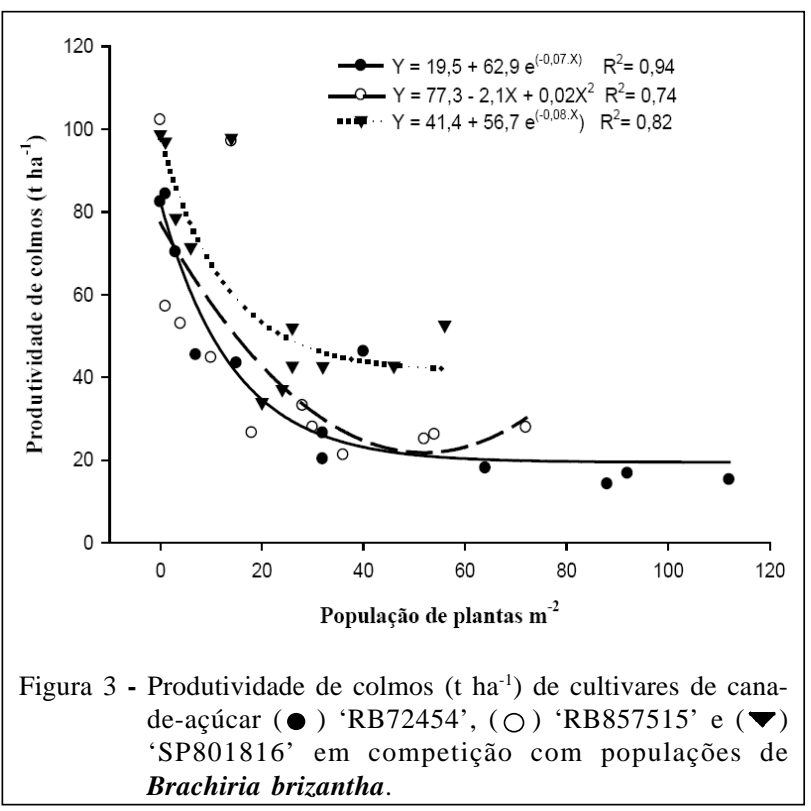

Ciência Rural, v.42, n.8, ago, 2012. 
produtividade de colmos de cana-de-açúcar devido à interferência de uma comunidade de plantas daninhas com predominância de espécies monocotiledôneas foi verificada por ROLIM \& CHRISTOFFOLETI (1982). Outro estudo relata redução de $82 \%$ quando a cultura esteve na presença do capim-braquiária (KUVA et al., 2001). De acordo com esses autores, vários são os fatores que podem interferir na produtividade da canade-açúcar quando em presença de plantas daninhas. No entanto, como se observou nesse trabalho, os fatores relacionados com a competição por nutrientes foram essenciais, pois, à medida que a população de plantas de $\boldsymbol{B}$. brizantha foi aumentando, de maneira geral, a concentração dos nutrientes N, P, K, e Mg foi reduzida, o que conduziu a menor produtividade da cana-de-açúcar.

A competição da $\boldsymbol{B}$. brizantha ocorre pelos fatores como água, luz, $\mathrm{CO}_{2}$ e principalmente nutrientes, bem como a diminuição da produtividade de colmos de cana-de-açúcar que ela ocasiona quando em altas populações. Essa espécie daninha também pode reduzir a longevidade dos canaviais brasileiros, hospedar grande número de pragas e doenças, além de animais peçonhentos, dificultar a colheita manual e mecanizada. Isso tudo faz com que o canavicultor tenha um maior custo com o manejo de plantas daninhas em lavouras de cana-de-açúcar.

\section{CONCLUSÃO}

A cultivar de cana-de-açúcar 'RB72454' apresenta menor habilidade competitiva por nutrientes ao competir com populações de B. brizantha. O aumento na população de $\boldsymbol{B}$. brizantha aumenta a massa da matéria seca dessa espécie e a competitividade com a cana-de-açúcar, reduzindo a concentração foliar dos macronutrientes, principalmente o fósforo. A cana-de-açúcar apresenta menor produtividade de colmos, à medida que aumenta a população de $\boldsymbol{B}$. brizantha, com redução média de 76\% na densidade máxima da planta daninha.

\section{REFERÊNCIAS}

BRAGA, J.M.; DE FELLIPO, B.V. Determinação espectofotométrica de fósforo em extratos de solos e plantas. Revista Ceres, v.21, p.73-85, 1974.

CARVALHO, L.B. et al. Interferência de Euphorbia heterophylla no crescimento e acúmulo de macronutrientes da soja. Planta Daninha, v.28, p.33-39, 2010. Disponível em: <http://www.scielo.br/scielo.php?script=sci_arttext\&pid=S010083582011000100008\&lng=en\&nrm=iso>. Acesso em: 13 mar. 2012. doi: 10.1590/S0100-83582011000100008.
CATUNDA, M.G. et al. Interferência de plantas daninhas no acúmulo de nutrientes e no crescimento de plantas de abacaxi. Planta Daninha, v.24, p.199-204, 2006. Disponível em: <http:/ /www.scielo.br/scielo.php?script=sci_arttext\&pid=S010083582006000100025\&lng=en\&nrm=iso\&tlng=pt $>$. Acesso em: 13 mar. 2012. doi: 10.1590/S0100-83582006000100025.

CHIEN, S.H.; MENON, R.G. Factors affecting the agronomic effectiveness of phosphate rock for direct application. Fertilizer Research, v.41, p.227-234, 1995.

GALON, L. et al. Níveis de dano econômico para decisão de controle de capim-arroz (Echinochloa spp.) em arroz irrigado (Oryza sativa). Planta Daninha, v.25, p.709-718, 2007. Disponível em: <http:/ /www.scielo.br/scielo.php?script=sci_arttext\&pid=S0100$83582007000400007 \& \operatorname{lng}=\mathrm{en} \& \mathrm{nrm}=\mathrm{iso} \& \mathrm{tlng}=\mathrm{pt}>$. Acesso em: 13 mar. 2012. doi: 10.1590/S0100-83582007000400007.

IKEDA, F.S. et al. Banco de sementes no solo em sistemas de cultivo lavoura-pastagem. Pesquisa Agropecuária Brasileira, v.42, p.1545-1551, 2007. Disponível em: <http://www.scielo.br/ s cielo.php? script=s ci_art t ext \& pid = S 0100 204X2007001100005\&lng=en\&nrm=iso\&tlng=pt $>$. Acesso em: 13 mar. 2012. doi: 10.1590/S0100-204X2007001100005.

KUVA, M.A. et al. Períodos de interferência das plantas daninhas na cultura da cana-de-açúcar. II - Capim-braquiária (Brachiaria decumbens). Planta Daninha, v.19, p.323-330, 2001. Disponível em: <http://www.scielo.br/scielo.php?script=sci_arttext\&pid=S0100$83582001000300003 \& \operatorname{lng}=$ en\&nrm=iso\&tlng=pt $>$. Acesso em: 13 mar. 2012. doi: 10.1590/S0100-83582001000300003.

LAMEGO, F.P. et al. Tolerância a interferência de plantas competidoras e habilidade de supressão por cultivares de soja I. Resposta de variáveis de crescimento. Planta Daninha, v.23, p.405-414, 2005. Disponível em: <http://www.scielo.br/ scielo.php? script=sci_art text \& pid=S 0100 $83582005000300003 \& \operatorname{lng}=\mathrm{en} \& \mathrm{nrm}=\mathrm{iso} \& \operatorname{tlng}=\mathrm{pt}>$. Acesso em: 13 mar. 2012. doi: 10.1590/S0100-83582005000300003.

MALAVOLTA, E. et al. Avaliação do estado nutricional das plantas. 2.ed. Piracicaba: Potafos, 1997. 319p.

PITELLI, R.A. et al. Estudo de competição inter e intraespecífica envolvendo Glycine max (L.) Merril e Cyperus rotundus (L.), em condições de casa de vegetação. Planta Daninha, v.6, p.129-137, 1983.

REIS JUNIOR, F.B. et al. Ocorrência de bactérias diazotróficas em diferentes genótipos de cana-de-açúcar. Pesquisa Agropecuária Brasileira, v.35, p.985-994, 2000. Disponível em: <http:// www.scielo.br/scielo.php?script=sci_arttext\&pid=S0100204X2000000500016\&lng=en\&nrm=iso\&tlng=pt $>$. Acesso em: 13 mar. 2012. doi: 10.1590/S0100-204X2000000500016.

RIZZARDI, M.A. et al. Competição por recursos do solo entre ervas daninhas e culturas. Ciência Rural, v.31, p.707-714, 2001. Disponível em: <http://www.scielo.br/scielo.php?script=sci_arttext\&pid=S0103$84782001000400026 \& \operatorname{lng}=e n \& n r m=i s o \& t \operatorname{lng}=\mathrm{pt}>$. Acesso em: 13 mar. 2012. doi: 10.1590/S0103-84782001000400026.

RODRIGUES, A.C.P. et al. Períodos de interferência de plantas daninhas na cultura do sorgo. Planta Daninha, v.28, p.2331, 2010. Disponível em: <http://www.scielo.br/ scielo.php? script =sci_arttext\&pid=S 0100 $83582010000100003 \& \operatorname{lng}=\mathrm{en} \& \mathrm{nrm}=\mathrm{iso} \& \ln \mathrm{l}=\mathrm{pt}>$. Acesso em: 13 mar. 2012. doi: 10.1590/S0100-83582010000100003. 
ROLIM, J.C.; CHRISTOFFOLETI, P.J. Período crítico de competição de plantas daninhas com cana planta de ano. Saccharum APC, v.5, p.21-26, 1982

RONCHI, C.P. et al. Acúmulo de nutrientes pelo cafeeiro sob interferência de plantas daninhas. Planta Daninha, v.21, p.219-227, 2003. Disponível em: <http://www.scielo.br/ scielo.php? script =sci_arttext \& pid=S 0100 $83582003000200007 \& \operatorname{lng}=e n \& n r m=i s o \& t \operatorname{lng}=p t>$. Acesso em: 13 mar. 2012. doi: 10.1590/S0100-83582003000200007.

SILVA, A.C. et al. Acúmulo de macro e micronutrientes por soja e Brachiaria brizantha emergida em diferentes épocas. Planta Daninha, v.27, p.49-56, 2009. Disponível em: <http:/ /www.scielo.br/scielo.php?script=sci_arttext\&pid=S0100$83582009000100008 \& \operatorname{lng}=$ en $\& n r m=i s o \&$ tlng $=p t>$. Acesso em: 13 mar. 2012. doi: 10.1590/S0100-83582009000100008.
SILVA, B.P. et al. Interferência de caruru-de-mancha, mariapretinha, picão-preto e tiririca em tomateiro industrial. Bragantia, v.69, p.313-318, 2010. Disponível em: <http:// www.scielo.br/scielo.php?script=sci_arttext\&pid=S0006$87052010000200008 \& \operatorname{lng}=$ en $\& n r m=i s o \&$ tlng $=p t>$. Acesso em: 13 mar. 2012. doi: 10.1590/S0006-87052010000200008.

SIMÃo NETO, M. et al. Avaliação da adaptação de acesso de Brachiaria para a Amazônia Oriental do Brasil. Pasturas Tropicales, v.17, p.9-13, 1995.

VIDAL, R.A. et al. Nível de dano econômico de Brachiaria plantaginea na cultura de milho irrigado. Planta Daninha, v.22, p.63-69, 2004. Disponível em: <http://www.scielo.br/ scielo.php? script =sci_arttext \& pid=S 0100 $83582004000100008 \& \operatorname{lng}=\mathrm{en} \& \mathrm{nrm}=\mathrm{iso} \& \ln \mathrm{g}=\mathrm{pt}>$. Acesso em: 13 mar. 2012. doi: 10.1590/S0100-83582004000100008. 